\title{
IMPACT ASSESSMENT OF BIOGAS PROJECTS IN LATVIA
}

\author{
J. PUBULE \& D. BLUMBERGA \\ Institute of Energy Systems and Environment, Riga Technical University, Latvia.
}

\begin{abstract}
During the last 5 years, more than 30 cogeneration plants where biogas is burned have been built in Latvia. The biogas plants help Latvia to comply with the European Parliament and Council Directive 2009/28/EC [1] on the promotion of renewable energy initiated on 23 April 2009. The directive states that the share of renewable energy must reach $40 \%$ of the total final energy consumption by 2020 . By using biogas produced in biogas plants, the share of renewable energy in Latvia has increased. At the same time, the production of biogas is new for this country; therefore, there has been a lack of a systematic approach in the planning procedure of biogas plants. An environmental evaluation of biogas plants during the planning process is essential. According to Latvian legislation, an Environmental Impact Assessment screening has to be performed during the biogas plants planning step. Within the research, quantitative and qualitative criteria for biogas projects evaluation are developed.
\end{abstract}

Keywords: Biogas projects, impact assessment, EIA, renewable energy, impact significance, Latvia.

\section{INTRODUCTION}

Each domestic activity generates an environmental impact. Before the activity commences, the potential impact of activities has to be assessed. One of the tools that is widely used and is included in the Latvian legislation is the Environmental Impact Assessment (EIA).

EIAs are applied to different projects, where there is a risk that the construction or operation may have a negative impact on the environment, as well as on human health.

Biogas production has many benefits. The first, and the main benefit, is related to new job creation and rapid rural development. Therefore, the development of the biogas sector stimulates the establishment of other enterprises and indirectly increases the income level and job opportunities in a given region. At the same time, the production of biogas has negative aspects as well: soil erosion, food/energy conflict and a substantial impact from the transportation of feedstock and digestate.

The first time the production and collection of biogas from biological processes was described was in 1895 in Great Britain. The process has developed considerably since those initial days.

Today, it is possible to produce biogas from different sources including wastewater sludge, manure, biowaste and algae as well. The energy crisis of the 1970s led to a new understanding of renewable energy sources, including the use of biogas energy produced through anaerobic fermentation.

Latvia, along with other countries, is intrigued by the use of biogas. This interest is related to the need to replace fossil fuels with renewable resources. In addition, there is a need to find environmentally sustainable solutions for the treatment and recycling of manure and organic waste.

In Europe, the production of biogas has increased dramatically over the last 10 years due to the growing demand for renewable energy as a substitute for energy carriers.

Most biogas plants in Europe use biogas for electricity production in combined heat and power (CHP) plants [2].

In Fig. 1, the main processes of biogas plant are shown.

Until 2007, only three biogas plants were operating in Latvia with a total installed electricity generating capacity of $7.5 \mathrm{MW}_{\mathrm{el}}$. Since 2009 , the number of biogas plants has rapidly increased in Latvia [4]. 
Currently, 58 businesses have received a quota for biogas production with a total installed electrical capacity of nearly $54 \mathrm{MW}_{\mathrm{el}}$.

In April 2011, there were 15 functioning biogas plants in Latvia with a total electrical capacity close to $19 \mathrm{MW}_{\mathrm{el}}$. In 2012, the total capacity of installed biogas plants in Latvia was $22.922 \mathrm{MW}_{\mathrm{el}}$. Thirty-five biogas plants were operational in 2012 in Latvia [5, 6].

The EIA screening of 39 biogas plants was completed in Latvia by the end of 2012 . So far, a full EIA procedure has not yet been applied or performed for any biogas plants.

In Fig. 2, the biogas plant network in Latvia is shown. The figure shows that the largest amount of biogas plants is located in the central part of Latvia, and a limited amount in the eastern and western parts of the country.

The aim of the screening phase of EIA is to determine if the project must be subject to an EIA. Without this verification some actions can be evaluated very precisely while others can be forgotten or ignored. While carrying out an effective assessment, a list with the activities planned, accompanied by the values and criteria for determining whether action should be evaluated, are formed $[7,8]$.

Categories of activities that are compulsorily required to carry out an EIA are defined in Annex 1 of the EIA directive. In Annex 2 of the directive, the operations that need to be undertaken in the EIA procedure on a case-by-case basis are defined. There may also be activities that are not included in these annexes, but the responsible organization of government after the screening has to decide to grant the EIA procedure to the activity. The state may also establish stricter limits, allowing certain

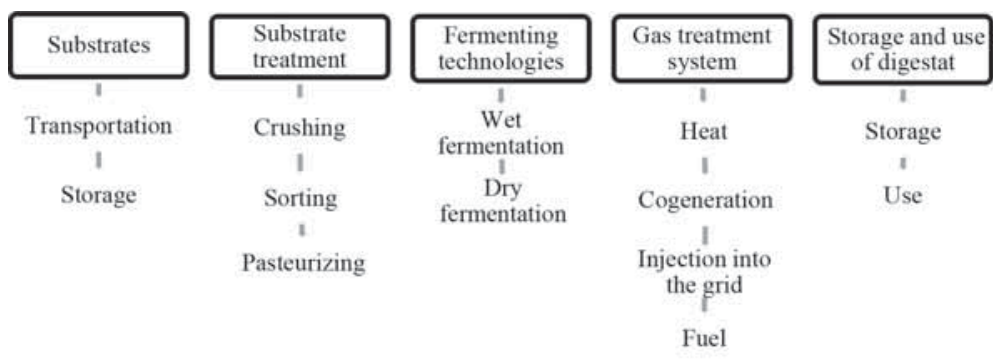

Figure 1: Biogas technologies process steps [3].

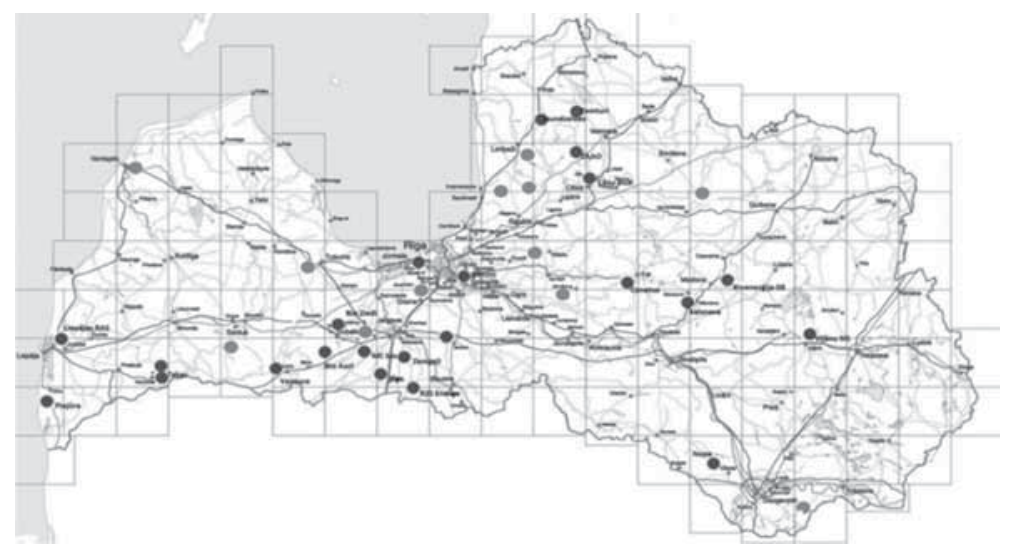

Figure 2: Biogas plants in Latvia [5]. 
projects to be subject to EIA procedure. The EIA procedure can also be made on a voluntary basis as an important step in developing the project [9].

Despite the fact that the EIA directive defines a uniform screening process, each country has implemented the EIA directive differently. Together with significant differences in regulations and practices of the initial inspection, the main shortcomings that have emerged are: doubts on the effectiveness of certain criteria and limits of systems for projects in Annex 1, non-systematic approach for the verification of projects in Annex 2, large differences in the initial test criteria between member states and the lack of clear definitions of the types of projects leading to possible misinterpretation of daily practice. Criteria that define the level of significance of the project vary depending on the quantitative or qualitative assessment. Predestined criteria are based on thresholds or previously taken measurements and specified restrictions and limits existing in laws, rules and other guidelines. Criteria based on the judgment are applied, if the project is unlikely to have a significant impact, but in the context the need to take precautions is justified.

\section{METHODOLOGY}

Within the framework of this work, a quantitative and qualitative analysis of existing biogas projects is performed. The work identifies qualitative and quantitative indicators of materiality of effect.

The research questions are answered mainly through a review of the relevant literature on EIA and biogas plant projects. The research methodology is based on a fusion of quantitative and qualitative research; the data concerning EIA in the Baltic States were collected through the archival analysis of relevant legislation, EIA reports, the use of questionnaires and semi-structured personal and focus groups interviews within the field and with EIA experts.

The study started with the analysis of the scientific literature and the theoretical basis of the production and the use of biogas and EIA formation worldwide. This was followed by the analysis of EIA legislation in Latvia. Furthermore, a survey of EIA reports in Latvia was performed.

\section{RESULTS}

In Latvian legislation, activities that must be carried out in EIA are clearly defined, as well as the scope of the work, which is carried out in accordance with international treaties, is clearly defined. At the same time, groups of activities subject to the screening are not well defined in the Latvian legislation, as well as the screening thresholds and criteria for evaluating the potential impact of the activity are not clearly defined. This leads to a very wide field of subjective judgments and indecisive approaches. By unreasonably reducing the number of projects that are subject to EIA procedure, the public's right to engage in discussion becomes limited and it is not possible for the public to comment on a project. The lack of laws, regulations and guidance complicates the decision-making and leads to conflict and makes it possible to use the lack of structure within the laws for selfish purposes.

According to the legislation, the application of the initial planned actions is filed at the regional environmental administration of the State Environmental Service, depending on the location of the planned activity. The regional environmental administration evaluates the material concerning the proposed project and decides whether it is necessary to perform a screening. By evaluating the laws and regulations, it was found that The Cabinet of Ministers of the Republic of Latvia has determined the order in which the screening of the environment is completed for the proposed action. The application procedures and application content are defined in the legislation.

According to Latvian laws and regulations on screening, the regional environmental administration is entitled to invite experts to evaluate, request and receive information from state and local government institutions, as well as to request and receive additional information from the project 
proposer. However, given the current economic situation, the government is not able to invite experts because there are no resources for the remuneration of experts [10].

\subsection{The screening of biogas projects in Latvia}

It is not possible to precisely define what is considered to be a significant impact on the environment. In the majority of the developed countries, where the EIA procedure is introduced, various methodological tools are developed to aid, so uniform potential of environmental impact evaluation in the screening process of proposed action could be made and a decision as to whether the activity should complete an EIA procedure could be taken. In most cases, such aids are made as questionnaires or a matrix.

The criteria of the significance of the impact include the description of the threshold value for identification [9]. The threshold values in Latvia are environmental quality standards, emission limit values and other limits and restrictions set in various legislations. Since the various restrictions and environmental quality standards vary in different areas and for various types of activities, then in most cases the significance of impacts is assessed individually in each case. Often the significance of the impact is not only dependent on the type and amount of hazard of the planned action but also the characteristics of the selected place have an important role. In some cases, the impacts of small objects that do not exceed the allowable thresholds are potentially dangerous if they are planned in a sensitive or congested area; therefore, these projects are applied to the EIA procedure. But at the same time, the relatively large objects with possible impact parameters similar to EIA application volumes may not require application of EIA procedure, because of the optimal choice of location and the projected technology that allows the impacts to be reduced to insignificant levels.

So we can say that the screening is one of the most important and responsible steps in the process of the EIA. A faulty decision could lead to substantial financial loss for the future performance of the project, if an unreasonable decision is made to apply the full EIA procedure, which requires substantial investments in both time and finances for the project.

Perhaps even greater losses are possible if technical regulations are not fully prepared because the possible impact is not fully assessed for the proposed action, and the implementation of the project has already started, while not realizing the potential problem situations and risk factors resulting in damage to the environment. It is known that in most cases, the consequences of the negative effects requires more resources and time than measures that could have prevented or reduced the possibility of the caused damage.

The EIA procedure in Latvia is known for more than 10 years. A lot of projects were analysed during this years.

If a classification of Latvia's biogas plants is needed, then they can be classified into three groups according to the used substrate:

1. The station, which produces biogas from wastewater treatment.

2. Stations where biogas is produced from the deposited waste of landfills,;

3. Stations where livestock and agricultural waste is used for biogas production.

What kind of biogas plants will be built in the future depends on several related factors. State support for electricity production from renewable energy resources (including biogas) is provided by the regulations of the Cabinet of Ministers. The regulations include a number of criteria for electricity producers from biogas to qualify for the mandatory purchase of electricity and ensure that the power producer will be able to sell electricity at a fixed price. When the situation is viewed from this perspective, it would be best for producers to build small plants, as this will provide more profit 
for each kilowatt hour produced. However, it should be kept in mind that the main criteria that the producer has to use while choosing what kind of station to install remain the availability of the used substrate and possibilities for the usage of produced energy [11].

As for the possible biogas plants in the future, there is a great potential for bird and pig farms, as well as regional landfills. Latvia is divided into 11 waste management regions. Despite the development of new landfills, organic fraction is not yet sorted from the stream of municipal solid waste in Latvia. In theory, all regional landfills are potential biogas producers, if the gas is obtained from sorted organic waste [12].

There are many landfill sites in Latvia where biogas production is possible, but the collection system of biogas is not yet built; however, the construction of such a system is planned for the future. During the period from 2008 to December 2012, the screening step was performed for 39 projects that have been classified as a biogas plant or a biogas cogeneration plant in Latvia. These projects are summarized and shown in Fig. 3.

As shown in Fig. 3, most of the procedures of the screening for biogas projects in the given period were completed in 2009, when the estimated number of projects was 13.

So far, a full EIA procedure has not been applied or performed for any biogas plants. By contrast, an $\mathrm{A}$ or B permit of polluting activities has been issued for 30 projects of biogas cogeneration facilities up until now. From these 30, the screening step has been completed for only 8 projects of biogas cogeneration plants. This means that the total amount of biogas planned plants is about 70 .

Not always can the successfulness of a particular biogas plant be assessed according to its individual technical specifications. Therefore, it is worthwhile to compare the technical parameters of planned and already constructed plants. To compare the effectiveness of biogas plants in Latvia, the amount of biogas produced from 1 ton of waste can be compared. Also, a good way to measure the yield of biogas is to compare the amount of biogas produced with the power of cogeneration plants where the produced biogas will be burnt.

\subsection{Feedstock for biogas plants in Latvia}

The total amount of substrates used for the production of biogas at the end of 2012 was approximately $1,000,000$ ton per year. The substrates used for biogas production are corn, manure, green fodder, biowaste, sludge, distillery refuses and landfill gas.

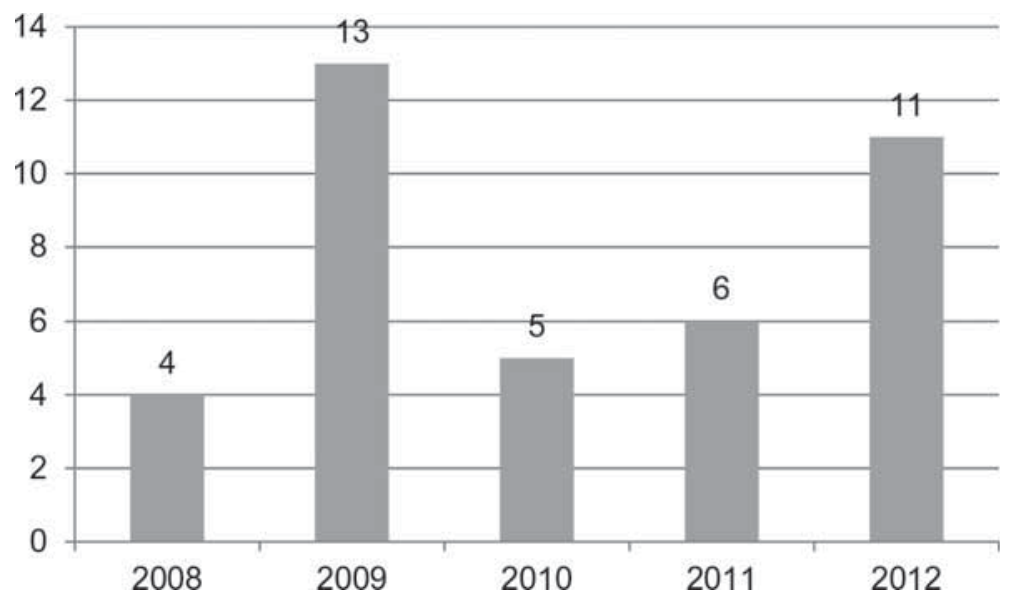

Figure 3: Biogas production projects for which the screening has been made from 2008 to 2012. 
The percentages of substrates used for the production of biogas are shown in Fig. 4.

Almost all biogas plants use different substrates for the production of biogas. The exceptions are only one landfill gas and one biogas plant producing biogas from wastewater sludge in the city of Riga. The total installed capacity (electrical and heat power) is approximately $40 \mathrm{MW}$, but at the same time heat is only used in a few cases. This means that in many cases the heat from the Cogeneration Heat Plant unit is not used, but wasted. New solutions must be found for the sustainable use of the biogas produced.

Twenty-five stations where livestock and agricultural waste is used for biogas production and one station that produce biogas from wastewater treatment were analysed during the research.

The substrates used in these plots are shown in Fig. 5.

The type of substrate used for biogas production affects the amount of produced biogas; therefore, the amount of substrate and capacity of the plant vary greatly. For example, from 1 ton of corn, it is possible to produce $202 \mathrm{~m}^{3} / \mathrm{t}$ of biogas, and at the same time, from the same amount of manure, it is possible to produce only $25 \mathrm{~m}^{3} / \mathrm{t}$ of biogas.

As well, the amount of biogas produced depends on the plant system, temperature and retention time. The organic load can influence the composition of the biogas substantially.

The division of anaerobic fermentation into wet and dry fermentation is only theoretical; microbiological processes take place in a wet environment. The difference is in the pumping characteristics of the substrate.

The composition of biogas varies. Mainly, the biogas composition depends on the type of substrate that has been used for biogas production. Mainly carbon monoxide $(\mathrm{CO})$, which is a product

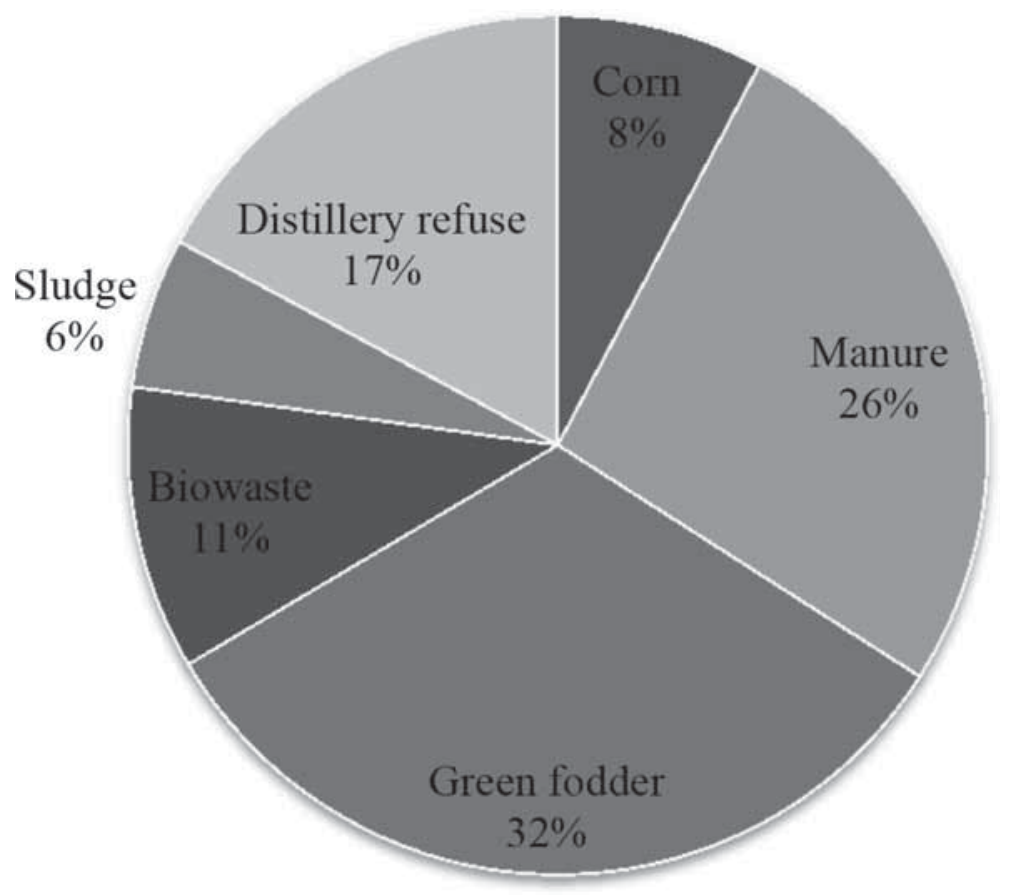

Figure 4: Substrates used for the production of biogas in Latvia (without landfill gas). 
of incomplete combustion, and nitrogen oxide compounds $\left(\mathrm{NO}_{\mathrm{x}}\right)$ are emitted while burning the biogas. Both of the above-mentioned gases are considered greenhouse gases.

Methane yields of selected feedstock are shown in Table 1.

Table 1 shows that corn fodder is one of the best substrates, because of the high biogas yield. In spite of this, only 7 of 35 biogas plants use corn fodder as a substrate for the production of biogas in Latvia. In Fig. 6, the most commonly used feedstock for biogas production in Latvia is shown. The most popular feedstocks are green fodder, manure and biowaste.

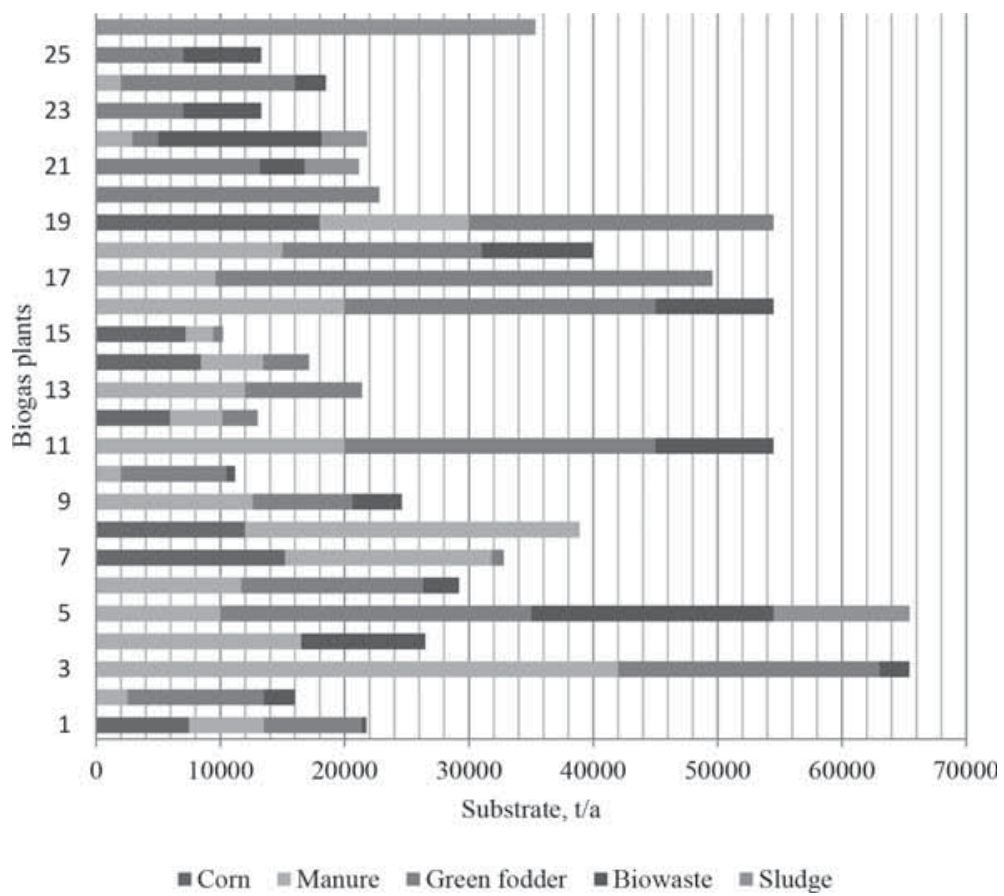

Figure 5: The use of substrates in biogas plants.

Table 1: Methane and biogas yields [3].

\begin{tabular}{lcc}
\hline Substrate/feedstock & Methane yield $(\%)$ & Biogas yield $\left(\mathrm{m}^{3} / \mathrm{t}\right)$ \\
\hline Wet cattle manure & 60 & 25 \\
Wet pig manure & 65 & 28 \\
Distillery refuse & 61 & 40 \\
Cattle manure & 60 & 45 \\
Pig manure & 60 & 60 \\
Poultry manure & 60 & 80 \\
Biowaste & 61 & 100 \\
Green fodder & 54 & 172 \\
Corn fodder & 52 & 202 \\
\hline
\end{tabular}




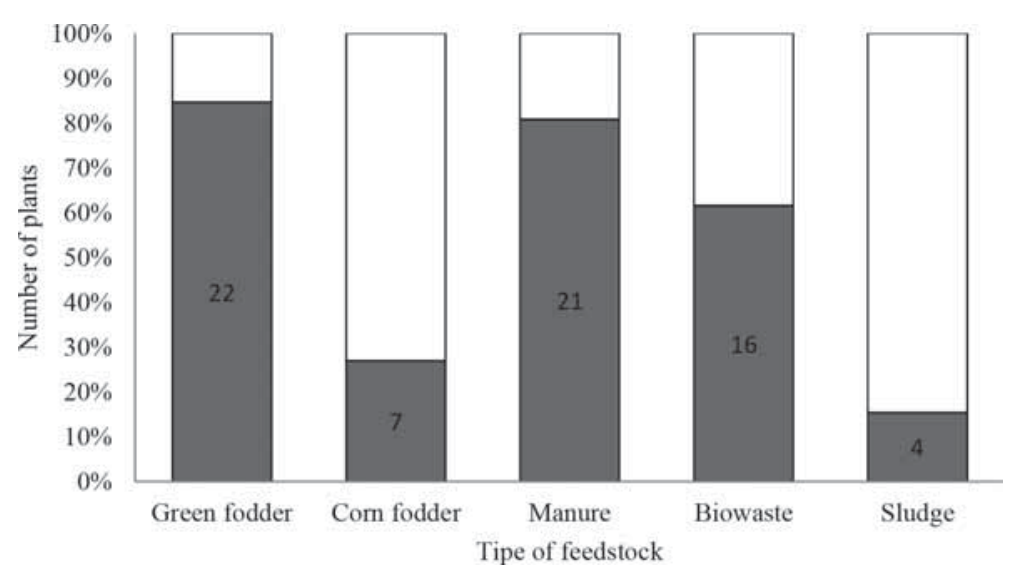

Figure 6: Substrates used for biogas production in Latvia.

European countries have to fulfil the Landfill Directive 1999/31/EC [13] and Directive 2008/98/ EC on waste [14] to reduce the dumping of the biodegradable part of municipal solid waste to $35 \%$. The Renewable Energy Directive (RED) 2009/28/EC [1] must also be followed.

The use of biowaste as a resource allows the EU to move closer to the common objectives by reducing the amount of waste disposed in landfills. On top of this, by using biowaste to produce something (biogas, compost) the reuse of waste materials increases. If biowaste is used to produce biogas, then the biogas upgrade to biomethane quality and the distribution of the biomethane through the natural gas network is an opportunity to efficiently use renewable energy in more populated (urban) areas and increase the energy independence of the country. This is a substantial amount that can now be recycled to avoid waste disposal. Unfortunately, the management of organic waste is not developed in Latvia. In Latvian waste legislation [15] only composting is mentioned as a product of biowaste and is mostly related to green waste. At the same time, at least seven biogas plants, which use biowaste as feedstock, started to operate in 2012.

\subsection{Impact assessment of biogas plants}

Special attention during the evaluation of biogas plants should be paid to these essential criteria: sustainability of the biogas plant; impact on air quality; occurrence of odours; occurrence of noise; impact on soil; impact on water and safety aspects of the station.

\subsubsection{Sustainability of biogas plants}

The sustainability of a biogas plant is one of the most important aspects of a biogas plants' EIA. The first biogas plants in Europe, as well as the largest part of the existing biogas plants in Latvia, operate inefficiently, because the heat from the CHP unit is unused or not maximized. Therefore, it is very important at the first stages of a project assessment to select projects for future development with an effective use of electricity and heat. In the future, it is necessary to develop biomethane projects, as well as projects where state-of-the-art technologies are used.

The operation of a biogas plant is related to different types of emissions going into the environment. If not treated properly, these emissions may leave an important impact on the environment as well as on human health. 


\subsubsection{Impact on air quality}

According to Latvian law, while modelling air emissions, any available and accepted methods in the world can be used for calculating emissions. That leads to a situation where different companies use different emission modelling methods and different emission factors. As a result, it is not possible to objectively evaluate the estimated emissions from various plants. In addition, at the moment companies often use the emission factors of natural gas during the modelling process, which should be unacceptable because biogas composition differs from natural gas composition.

It is, therefore, necessary to develop a uniform methodology for the calculation and modelling of air emissions of biogas plants.

\subsubsection{Occurrence of odours}

Substrates used for the production of biogas volatile organic compounds (e.g. iso-butonic acid, butonic acid, iso-valeric acid and valeric acid, along with at least 80 other compounds) produce unpleasant odours.

Anaerobic digestion significantly reduced the concentration of many of these compounds, such that their potential for giving rise to offensive and lingering odours during storage and distribution has been significantly reduced. Thereafter, the use of appropriate distribution methods can prevent the release of any residual odour. Therefore, it is important to minimize the disturbance of the excrement during its transfer from the storage tank [16].

In the case of biogas projects, public awareness and participation is an important factor for successful project implementation. It is very important to inform the public about the project in the very first stage of the development of the project.

\subsubsection{Occurrence of noise}

The CHP station has to comply with European noise regulations. Noise emissions during the biogas production derive mainly from the production machines - air and exhaust fans, the cooler of the mixer and the flue. Similarly, noise also arises from the transport which delivers the raw material to the biogas plant. If most of the noise from the production installations is unavoidable, then in relation to noise arising from transport, it can be optimized by planning the transportation of raw materials during the day.

\subsubsection{Impact on soil}

In accordance with Latvian legislation, territories where pollution may have an increased effect on human health or the environment and its biological diversity, or the territories that are highly sensitive to pollution load shall be known as highly sensitive territories [17]. The largest part of biogas plants in Latvia is located in highly sensitive territories (see Fig. 7).

During the evaluation of environmental impacts in highly sensitive territories, special attention must be paid to the use of excrement and protection against leakage during the running of a biogas plant.

Emissions to water bodies have to be avoided during the operation of a biogas plant [18].

\subsubsection{Impact on water}

As well, all related water regulations have to be considered. In accordance with Latvian regulation, the minimum distance between watercourses needs to be between 10 and $500 \mathrm{~m}$ depending on the size of the water source [19].

\subsubsection{Safety aspects of the station}

In the permit required for a biogas plant to run, it is necessary to include an assessment of various preventive and damage control measures. In such cases, these include: explosion prevention; fire 


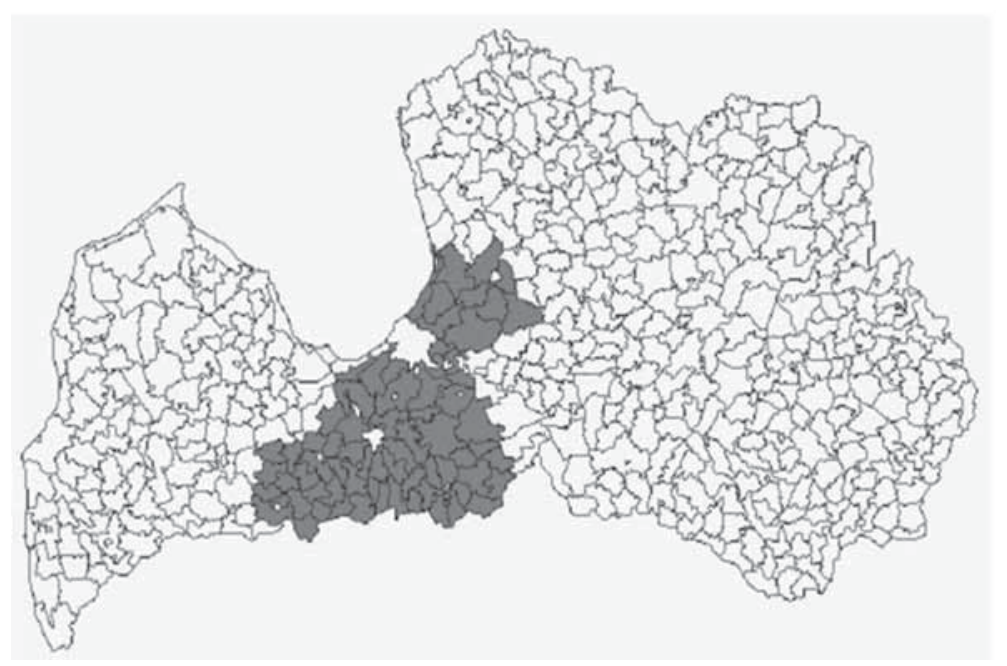

Figure 7: Highly sensitive territories [16].

prevention; mechanical hazards; sound-proof design; electrical safety; lightning protection; thermal safety; asphyxiation and poisoning prevention; hygiene and health safety.

\section{ANALYSIS OF ENERGY EFFICIENCY}

During the energy efficiency research, 33 biogas cogeneration plants were analysed. The installed capacity of these plants varies from 0.25 to $6.28 \mathrm{MW}$. Figure 8 shows the installed capacities of biogas cogeneration plants.

Biogas cogeneration plants operate with varying capacity, and only a few plants are currently operating at full capacity throughout the whole year. This leads to an additional load to the environment. The operation ratio (1) is written as follows:

$$
\mathrm{K}=\mathrm{E}_{\mathrm{actual}} / \mathrm{P} * \tau,
$$

where $\mathrm{K}$ is the operation ratio; $\mathrm{E}$ the actual electricity generation, $\mathrm{MWh} / \mathrm{year}$; $\mathrm{P}$ the installed capacity, MW and $\tau$ the operation, h/year (assumption $8000 \mathrm{~h} /$ year).

Figure 9 shows that the majority of the biogas cogeneration plants operate part-time, with partial capacity. Only four stations operate with an optimal load in accordance with the projected capacity. These plants have feed-in tariffs, and the production of electricity is economically feasible. As well, there is a tendency that demonstrates that the production of electricity is higher when a power station operates with a full load throughout the year. Therefore, an analysis and impact assessment of biogas plants must be done during a period of operation.

\section{DISCUSSION}

Existing and planned biogas plants play an important role in the energy independency of Latvia. The target for renewable energy sources by 2020 for Latvia can be achieved, if energy sources are constructed where fossil fuel is replaced with a renewable one.

The study shows that the existing screening process of EIA in the field of biogas plants can be more effective. To achieve this, a set criteria should be used. This would allow for parties to establish and describe the impacts and the degree of the significance related to carrying out the screening of biogas plants. 


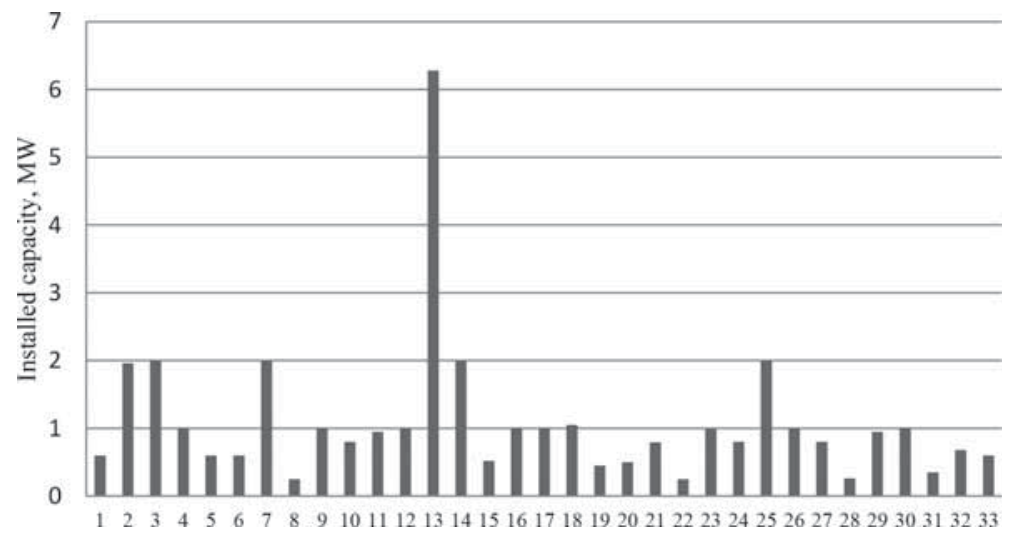

Figure 8: Installed capacity of biogas cogeneration plants.

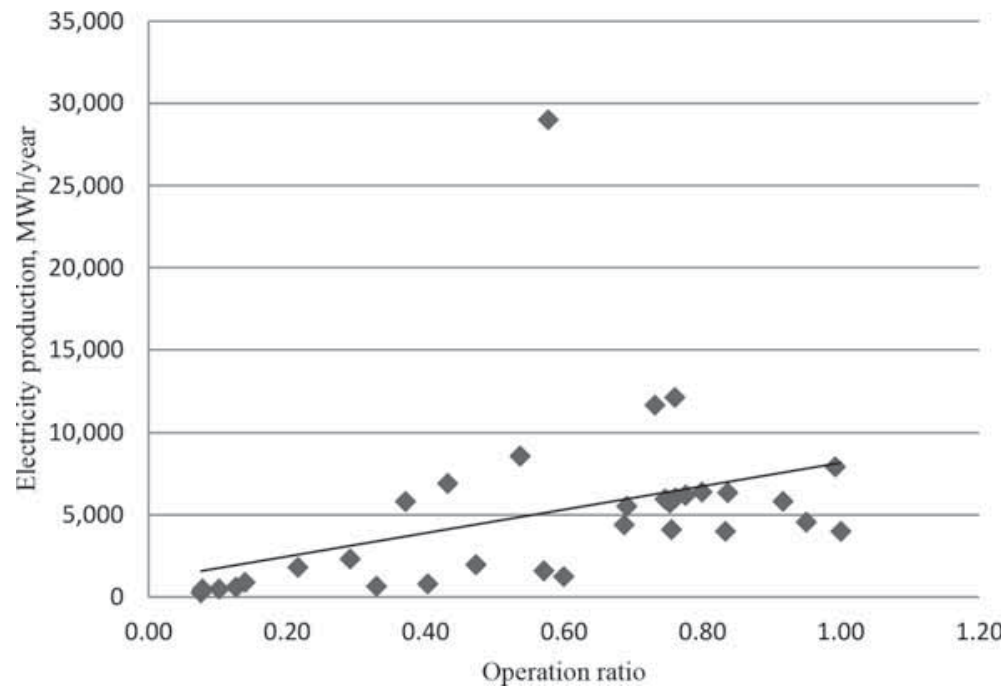

Figure 9: Production of electricity depending on operation ratio.

It is essential that the first stages of a project assessment select projects for future development with an effective use of electricity and heat.

In the future, it is necessary to develop biomethane projects, as well as projects where state-of-the-art technology is used. The optimization scenarios for the most efficient use of the heat from biogas CHP units should be found.

Further research about the possibility to use existing biogas plants in Latvia for the treatment of biowaste, collected separately from households, should be done.

\section{ACKNOWLEDGEMENT}

This work has been supported by the European Social Fund within the project "Support for the implementation of doctoral studies at Riga Technical University". 


\section{REFERENCES}

[1] European Commission, European Parliament and Council Directive 2009/28/EC of 23 April 2009 on the promotion of the use of energy from renewable sources, Official J. L 140, pp. 16-62, 2009.

[2] Rutz, D., Mergner, R. \& Janssen, R., Sustainable Heat Use of Biogas Plants. A Handbook. WIP Renewable Energies: Munich, Germany, 2012.

[3] Blumberga, D., Veidenbergs, I., Romagnoli, F., Rochas, C. \& Zandeckis, A., Bioenergijastehnologijas. RTU Institute of Energy Supply and Environment, Latvia, 2011.

[4] Pubule, J., Bergmane, I., Blumberga, D. \& Rosa, M., Development of an EIA screening phase for biogas projects in Latvia. WIT Transactions on Ecology and the Environment, 162, pp. 75-86, 2012. doi: http://dx.doi.org/10.2495/EID120071

[5] Karklins, A., Review of Latvian biogas market. Future plans. Proceedings of 4th Latvian Green Energy Forum. RTU: Riga, 2011.

[6] Karklins, A., Actualities in production of biogas in Latvia and Europe: Proceeding of Biogas projects development and possible risks conference. Latvian Biogas Association: Riga, 2012.

[7] Toro, J., Requena, I. \& Zamorano, M., Environmental impact assessment in Colombia: Critical analysis and proposals for improvement. Environmental Impact Assessment Review, 30, pp. 247-261, 2010. doi: http://dx.doi.org/10.1016/j.eiar.2009.09.001

[8] Kornov, L. \& Prapaspongsa, T., Environmental Impact Assessment II. Aalborg University: Aalborg, 2011.

[9] Koornneef, J., Faaij, A. \& Turkenburg, W., The screening and scoping of environmental impact assessment and strategic environmental assessment of carbon capture and storage in the Netherlands. Environmental Impact Assessment Review, 28, pp. 392-414, 2008. doi: http://dx.doi.org/10.1016/j.eiar.2007.08.003

[10] Pubule, J., Blumberga D., Romagnoli F., et al., Analysis of the environmental impact assessment of power energy projects in Latvia. Management of Environmental Quality: An International Journal, 23(2), pp. 199-203, 2012. doi: http://dx.doi.org/10.1108/14777831211204930

[11] Wood, G., Thresholds and criteria for evaluating and communicating impact significance in environmental statements: 'See no evil, hear no evil, speak no evil'? Environmental Impact Assessment Review, 28, pp. 22-38, 2008. doi: http://dx.doi.org/10.1016/j.eiar.2007.03.003

[12] Blumberga D., Dzene, et al., Biogas. Handbook. University of Southern Denmark Esbjerg: Esbjerg, Denmark, 2011.

[13] European Commission, Council Directive 1999/31/EC of 26 April 1999 on the landfill of waste, Official J. L 182, pp. 1-19, 1999.

[14] European Commission, European Parliament and Council Directive 2008/98/EC of 19 November 2008 on Waste, Official J. L 312, pp. 3-30, 2008.

[15] Waste Management Law: Republic of Latvia Law//Official Journal of RL "Latvijas Vēstnesis", No. 183(4375), 17.11.2010.

[16] Daublein, D. \& Steinhauser, A., Biogas from Waste and Renewable Resources. An Introduction. Second, Revised and Expanded Edition. Wiley-VCH: Weinheim, 2011.

[17] Law on Pollution: Republic of Latvia Law//Official Journal of RL "LatvijasVēstnesis", No. 51(2438), 15.03.2001.

[18] Rutz, D. \& Güntert, D., Biogas Checklist for Administrative Bodies. WIP - Renewable Energies: Munich, Germany, 2012.

[19] Protection Zone Law: Republic of Latvia Law//Official journal of RL "Latvijas Vēstnesis", No. 56/57(771/772), 25.02.1997. 